\title{
Material returns: Cultures of valuation, biofinancialisation and the autonomy of politics
}

Simon Lilley \& Dimitris Papadopoulos

\author{
Sociology \\ bttps:// doi.org/10.1177/0038038514539206
}

\begin{abstract}
The ascent of biofinancialisation since the 1980s brought with it a culture of valuation that spread well beyond financial markets and came to pervade everyday life, subjectivity, ecology and materiality. At the same time, and as a response to the social conflicts of the previous decades value production shifts to incorporate the extended lifeworld of working people, their networks of sociality and the commons. The paper examines the conflicts that emerge from the friction of the prevalent cultures of valuation and the extensive embodiment of value production and argues that biofinancialisation alters the very material infrastructure of bodies and forms of life. What is the autonomy of politics when biofinance becomes molecularised in code and in matter?
\end{abstract}

\section{Keywords}

Autonomy of Politics, Biofinancialisation, Commons, Materiality, Science Fiction, Social Science, Social Studies of Finance, Terraformation, Valuation, Value Production

\section{Acknowledgments}

We are grateful to Andrea Ghelfi, Nikos Karfakis, Geoff Lightfoot and the editors and reviewers of this special issue for their insightful comments. Various events and debates at the Centre for Philosophy and Political Economy, School of Management, University of Leicester, the symposium Organising the Commons at the University of Leicester, the workshop What price creativity? The valuing of social/public goods at the University of St Andrews and the Critical Management Studies Manchester conference were crucial for developing the ideas presented here.

\section{Bio}

Simon Lilley is Professor of Information and Organisation and Head of the School of Management, University of Leicester. His research turns around the relationships between (human) agency, technology and performance and particularly the ways in which such relationships can be understood through post-structural approaches to organization. These concerns are reflected in a range of publications, including Representing organization: Knowledge, Management, and the Information Age (Oxford University Press 2004), that focus upon the use of information technologies and strategic models in organizations and the regulation and conduct of financial and commodity derivatives trading.

Dimitris Papadopoulos is Professor of Science, Technology and Society and Director of the Institute for Science and Society at the University of Nottingham. His work in science and 
technology studies, social theory and social change has been published in numerous journals and in several books. He is currently working on a monograph called Chemopolitics and Elemental Justice and a co-edited volume called Reactivating Elements. Substance, Process and Method from Chemistry to Cosmology (forthcoming with Duke University Press) which examine elemental thinking and the becoming ecological of chemical practice. His most recent book, Experimental Practice. Technoscience, Alterontologies and More-Than-Social Movements (Duke University Press 2018), investigates how community technoscience, social innovation projects and the distributed invention power of social movements change the meaning of politics and justice today. Previous books include: Escape Routes. Control and Subversion in the 21st Century (Pluto Press 2008), Analysing Everyday Experience: Social Research and Political Change (Palgrave 2006) and Lev Vygotsky: Work and Reception (Campus 1999/Lehmanns 2010). 
The current financialised regime of accumulation has become embodied in the very ontology of our everyday lives to such a large extent that even those social groups that are potentially able to challenge its legitimacy cannot do it without challenging their very existence. This is more than a mere intellectual problem, or an issue of (lack of) parrhesia, courage and social responsibility; ${ }^{1}$ biofinancialisation--that is financialisation at the level of everyday life, subjectivity, ecology and materiality--is an issue that poses questions about the current architecture of control and about the prospects of taking exception to it.

The effect of biofinancialisation is that it has propelled the engulfment of large segments of Global North societies into a mode of existence that has changed the conditions for the articulation of social and political alternatives. Despite the predicament of politics that we are experiencing in the Global North and despite the powerful mobilisations that have shaken many countries since 2008 , a turning point seems almost impossible. This situation is defined not only by economic and political exigencies but also by the fact that alternative forms of politics that were put in motion in the past decades seem unable to create fertile conditions for social change. We rely on readings from science and technology studies as well as the practices of recent social mobilisations in Global North societies and on science fiction literature to explore the meaning of politics in these conditions.

\section{$\underline{\text { Social conflict and the culture of valuation }}$}

Today's responses to the economic crisis have their roots in the ways the unruly social and political movements after the 1960s were gradually reinserted into the current biofinancialised regime of accumulation. The contentious mobilisations of the working classes and subaltern populations which started in the 1960s and 1970s put an end to the Fordist-Keynesian accumulation model by challenging the cultural, racial and sexual organisation of labour on a local and global scale. ${ }^{2}$ These struggles transformed gradually and diversified through the 1980s and 1990s to a multiplicity of social mobilisations and conflicts that forced social regulation to reorganise itself in order to capture the new exiting subjectivities: migrant mobilisations, feminist struggles and social rights mobilisations, the alter-globalisation movement, ecological movements.

These contentious politics intensified with the relocation of production outside the Global North and with the elevation of financial markets to one of the primary engines for economic recovery after the crisis of the 1970s (Duménil and Lévy 2005). This crisis never ended in the destruction of value nor in the creation of a new system for the invigoration of demand by changing the living conditions of the populations through a new 'New Deal'. Rather we entered into a perpetual crisis that paradoxically became the cause as well as the consequence of a new regime of social production dominated by stagnant wages, underemployment and the flexibilization of labour markets as well as of finance-led accumulation with the introduction of securitisation and increased consumer and corporate lending. Financialisation on the one hand and the deregulation of labour markets on the other became the key features of the neoliberal turn after the 1970s.

What is crucial for the argument of this paper is that these transformations are not mere instruments for social regulation or economic tools for counter-acting the socioeconomic troubles that took place after the 1970s. Their effects are far more important than 
their economic performativity. In other words, the economic quandaries were not primarily resolved through financial means but through social, cultural and techno-material transformations (that were enhanced by new economic devices and accounting techniques) ${ }^{3}$. The virtualisation of the economy that dominated the post 1970s crises was not just an economic strategy. It is culture. Financialisation is culture. Not only because it came to pervade the everyday, as Randy Martin (2002) has described, ${ }^{4}$ but also because it contributed to the consolidation of an ever expanding culture of financial valuation of goods and services (see for example Barbier and Hawkins 2012; Beckert and Aspers 2011). This is the tendency to translate disparate judgements about value to financial measurements that introduced a culture of valuation into everyday life. Any and all aspects of socio-material life and the environment enter into this indeterminate and unstable process of evaluation that feeds the movements of financial markets and financialised societies.

The underlying logic of the culture of (financial) valuation is that the worth of goods, things, activities and spaces can be essentially translated into financial evaluations. Although different scales of evaluation are by definition incommensurable the predominance of the culture of valuation in Global North societies presupposes and promotes that the worth of almost everything--including the present and future appreciation of assets, goods, services, intangibles, the health and subjective capacities of individuals, the physical environment, human artefacts, other species, urban space--is in principle transferable into one single logic of financial value that is potentially tradable in the market: this is biofinancialisation. ${ }^{5}$ Neither valuation as such nor the cultures of valuation are novel and distinctive features of the current period; what is distinctive however is that the different forms of value--and, indeed, radically divergent values--are imagined as convertible into financial value. Financial value is here used to express the primacy of investment value over other values (aesthetic, use, moral, ecological, material, cultural) that predominantly assess the future monetary profit to be gained from potentially any field of life or the environment. The principle of investment value hinges upon the belief that the future is exploitable.

\section{$\underline{\text { Biofinancialisation }}$}

The imaginary of measurable future value lies at the heart of the current culture of valuation that traverses many different fields of life. For example, we have investigated how young precarious workers 'invest' in themselves by shaping their current activities according to the possible future gains in unstable labour markets or how bio-matter of life is evaluated according to future monetary gains from its potentially scientific or commercial exploitations. ${ }^{6}$ These are just two examples. What is crucial here is that value becomes an intrinsically indeterminate magnitude that has to be calculated by creating appropriate measuring tools ${ }^{7}$ and then defended and negotiated between experts in designated public spaces or in the secluded spaces of the markets. Future value is by definition unpredictable and in order to be realized the actors involved need to experiment, to manage conflicting information and to create knowledge in action. ${ }^{8}$ Future value and investment value are recombining other forms of value into a process of uncertainty. These valuation clashes and the frictions between different systems and scales of values constitute the emerging culture of valuation in biofinancial societies. 
The ascendance of biofinancialisation and the concomitant culture of valuation goes hand in hand with another set of responses to the social conflicts and the crises of the 1970s and 1980s that thoroughly transformed the process of value production. Deregulation of labour markets, the retreat of organised labour, the collapse of Fordism, deindustrialisation and the steep increase of the service and retail sector over the steady decline of manufacturing as well as the proliferation of atypical and precarious labour--all become core features of the decline and transformation of industrial production in Global North societies into what many authors have described as a third stage in the development of the system of production. ${ }^{9}$

Industrialism in the Global North became increasingly hybridised by the expansion of the service sector (professional high skilled work as well as low-paid, non-standard and insecure work), the rise of the knowledge and culture economy, the accumulation of wealth through the production of intangible goods and the extraction of surplus value from consumption, communication and social reproduction. The biofinancialised regime of accumulation relies on a double architecture of production: on the one hand it mobilises the existing system of value production in its industrial formation in order to regulate the immediate labour process (through the traditional system of wage labour and remuneration); on the other hand it relies on the appropriation of broader aspects of social and material life, everyday activities, resources of cooperation, working people's general skills and subjective capacities that are not strictly involved in the immediate labour process. ${ }^{10}$ The architecture of value production in biofinancial accumulation extends beyond the workplace and relies on the expropriation of res communes: the commons, common pool resources and common forms of sociality and relationality that are neither public nor private.

The commons does not only refer, as broadly used in social movements, to a possible social force that could resist its own expropriation but also constitutes, simultaneously, the underlying system of production of biofinancial accumulation. Biofinancialisation--the financialisation of life--is here specifically used to describe how the commons becomes the ground and the material substratum on which biofinancial accumulation thrives. Openly and commonly used infrastructures (information and communication technologies, collaboratively produced knowledge, cultural networks), the material commons and the environment as well as structures of cooperation, everyday sociality and exchange between producers and consumers make up some of the main sites of value production. Biofinancialisation flourishes because it extracts value from reproduction, distribution and consumption as well as other activities and the material surroundings which do not directly belong to the immediate sphere of production; and this is possible because appropriation of labour in the workplace is organised through the specificities of the lives of working people beyond the workplace itself.

\section{Embodying value production}

The externalisation of production from the workplace to the social and the material does not mean that the site of value production is transferred 'outside' living labour. Duration of the working day and increase of work are considered to be the main two dimensions which intensify the degree of appropriation of living labour. But this intensification of appropriation affects--and to a large extent entails and necessitates--a wider set of activities that extend beyond the immediate work related activities. One could say that the supposed intensification 
of appropriation is complemented by its extensification. Value production expands across the whole existential conditions of living labour, the lines of fight and control multiply and traverse different domains of life.

Activities that people perform as part of their non-work life or secondary activities of their work life become directly productive. Beyond that it also means that working people mobilise multiple social and personal investments in order to be able to remain in the labour market (e.g. social relations, general skills, informal networks, ideas, their subjectivity, their mobility, their health, their self-organised structures for cooperation, their potential for development)--some of this is entailed in the 'final product' of their labour, but much remains outside of it. The epicentre of value production is the workplace, but it is only the epicentre. If we would only focus on the workplace we would miss the important and sometimes defining broader conditions in which work and employment take place. ${ }^{11}$ However, the extensified mode of value production does not mean that work becomes simply dispersed and socialised, that it moves outside the singular worker. It rather means that value production becomes embodied: it becomes an indissoluble characteristic of the whole situated social existence of each singular worker. The situated and embodied quality of work includes all things and artefacts that constitute the worlds in which we exist, our social relations as well as the broader networks of the commons that we rely on to maintain everyday life.

The separation of labour power and living labour, a separation that was possible in the system of production of industrialism, becomes the major source of conflict in biofinancial societies, simply because living labour in its embodied and situated wholeness is the source and vehicle of labour power. Control over embodied production is taking place along several lines that attempt to cut across and appropriate the existential continuum of people: Firstly, the attempt to measure labour-power and to quantify it despite the fact that it mobilises the whole embodied conditions of life (De Angelis and Harvie 2009); secondly, the expropriation of the infrastructures of cooperation through property rights, patents and the re-privatisation of access to and circulation of information (Bollier 2008); thirdly, the individualisation of the costs of social reproduction and privatisation of those forms of social reproduction that cannot be taken up by the individual (Barbagallo and Federici 2012); fourth, the transformation of citizenship to a tool for creating various tiers of working people whose degree of labour appropriation depends on their varied access to citizenship rights (Alberti 2011). One could say that all these lines break the horizontal and continuous lived experience of working people and create some form of separate vertical segments that become the productive engine of the biofinancial regime of accumulation. Vertical life. Walls of value.

\section{Culture of valuation as a factor of political stability in biofinancial societies}

The attempt to impose a separation between product of work and process of work, of cooperative ownership and proprietary ownership, of production and social reproduction that is, in other words, an attempt to impose the law of value and the system of wage labour constitutes the fault lines of embodied value production. The main conflict is between an extended process of value production that is experienced as indissoluble from everyday existence and the attempt to control, organise and remunerate this system according to the 
immediate labour needed for the production of value. In other words, the conflict lies in the fact that value production is embodied but it is treated as if it is external to the singular worker. This conflict--which threatens to erupt anytime and to throw the balance of power into disorder--is not the result of the uncontrollable economic forces that emerged with the turn to financialisation; rather it is the result of the deep social conflict that traverses embodied value production as a whole (Lilley and Lightfoot 2014).

The instability of biofinancial societies 'has nothing to do with any presumed instability per se of the mechanisms of the financial system; quite the contrary, the ambition of those mechanisms is precisely to absorb shocks and to smooth out discontinuities in the economic cycle' (Moulier Boutang 2012, 152). Here is where the culture of valuation described earlier in this paper meets the production of value in today's conditions. The culture of valuation does not only underpin the system of finance-led accumulation but also absorbs the shocks of the social conflicts that traverse embodied value production. Thus the instability and the conflicts that lie in the heart of value production are not intensified by the indeterminancy of the culture of valuation, rather the opposite is the case: the culture of valuation that comes to dominate the socio-material regime of accumulation is the main tool through which conflict in value production is regulated (and potentially also contested, as we will discuss later). The pervasiveness of the culture of valuation with the crucial indeterminancy of value that lies at the core of this culture is the main way to control the outputs of work in the extensified mode of production and, simultaneously, also serves as the vehicle which working people themselves deploy to modify and change their position in the social nexus. Financialisation turns 'bio' not only because it is actively embedded in people's lives, bodies and their environments but precisely because this embeddedness, this becoming fleshly of financialisation, came to constitute anew how social conflict unfolds and social struggles are performed. As financialisation becomes an integral part of value production, it becomes also the vehicle for articulating social demands and political claims. Financialisation is culture because it came to dominate our imaginary to such an extent that even social justice can be fought for with financial means. Financialisation is not ideology; it is as real as something can be: engrained in the everyday ontology of life.

The effect of biofinancialisation is not only that it created the ground for a new phase of expansion (and crisis) but also that with the culture of valuation it created a tool for managing the conflicts that traverse embodied value production. ${ }^{12}$ It is through biofinancialisation and more broadly the culture of valuation that specific segments of the elites and the middle classes maintained and strengthened their position in the social order over the past 40 years. The ascent of managerial and professional classes and their privileged access to education and socio-cultural capital have contributed to the expansion and consolidation of the middle class in the postwar period. The lack of significant opposition to the 'austerity measures' and the meagre responses to the crisis is not only imposed but also desired by a broad social coalition that includes the elites and middle classes (and certain segments of the emergent working classes and service workers). This might offer an explanation of why a change of this stance seems not only unlikely but is also feared by wide segments of Global North societies.

The end of the refusal of work 
This is a political situation that is defined by a deep immanent conflict: the verticalisation and appropriation of the commons and everyday life (as discussed earlier, through measure, proprietary regimes, the individualisation of social reproduction and the transformation of citizenship to a tool for the regulation of labour markets) undermines working people's everyday lives and the flow of embodied value production; at the same time the verticalisation of the commons is the condition for maintaining the current socio-material regime of accumulation as well as the balance and stability of political power in current biofinancial societies. The main political responses to this situation are guided by some form of revival of autonomous political practices that played a role in the 1970s and 1980s, in particular the politics of the refusal of work and the self-organisation of social reproduction: an exit from work towards activities that lie outside capitalist valorisation and the organisation of immediate social life outside of formal public services or private provision. ${ }^{13}$ But when value production becomes literally embodied in the very existence of working people, as argued earlier, these political alternatives seem almost impossible. Production no longer operates through an externality between the subject and her work, but through accumulation of the embodied totality of one's own biofinancialised existence. Equally, large scale self-organised social reproduction in the sense that has been described in places outside the metropolises of the Global North (e.g. Zibechi 2011) seems an untenable political scenario simply because it is impossible to give up work in its embodied configuration in order to free space for selforganising social reproduction.

Bifo delivers an intriguing description of the mixture of everyday life and the biofinancial regime, but his vision that 'autonomy is the independence of social time from the temporality of capitalism' (Bifo Berardi 2009, 75) does not seem to hold against the carnal orgy of contemporary biofinacialisation's feasting on the commons. One cannot say as an expression of autonomy today 'I don't want to go to work because I prefer to sleep'. The refusal of work is impossible not only de facto--that is because work is indissoluble from the body of working people, animals and things--but also because it is not desired: verticalised value production has become the condition for maintaining everyday existence within the social order. We can exist and make a life only through the biofinancialised bodies we have. One can only say 'I no longer can work' and be punished, as Bifo so aptly describes, with stigma, panic, depression and the deactivation of one's own capacity for empathy (Bifo Berardi 2011). But neither can empathy be infused to the social body nor panic and stigma just simply extracted from it, as if they are external to it; neither Prozac nor poetry, neither Ritalin nor mindfulness are enough to do this--they inhabit the social body and when they move from one individual body to the next, they leave their traces on them, they mark life for ever.

Thus, cultures of valuation are inextricably linked to everyday life and the creation of value while many of alternative political responses mentioned earlier are trapped in the increasingly exceeded logic that value is mainly created in a system of wage labour that is supposed to be external to the broader conditions of people's everyday existence. Even approaches ${ }^{14}$ that try to resuscitate some form of subtraction from labour towards selforganised alternative productive activities neglect the fact that even these activities sustain the broader system of embodied value production even if they are not directly implicated in market activities. In biofinancialised societies value is not only created through labour in the 
production process; rather, value creation shifts to a multiplicity of activities and sites that overdetermine the practice of labour. Labour does not cease to be one of the major sites of value production. But now labour and value production cannot exist without all these practices that contribute in complex ways to sustain a form of existence that is governed by an intense culture of valuation connecting different aspects and activities of one's life. In the same way that political economy as we know it does not offer adequate concepts to grasp this political impasse, the refusal of work does not offer a political alternative to biofinancialised existences. In order to establish how alternative political responses to biofinancialisation have been rendered obsolete it is important to explore how the culture of valuation came to permeate the very ontological constitution of life.

\section{Performing biofinancialisation}

A possible way to start thinking the political impasse of biofinancialised societies is offered by the analyses of social studies of finance which investigate clashes over the valuation of circulating financial objects and reveal that these objects are active agents that shape the institutions, markets and social spaces in which they operate. ${ }^{15}$ Their valuation is not a straightforward process. What social studies of finance allow us to understand is that these phenomena cannot be approached with the means of political economy because their technoscientific ontology, ${ }^{16}$ their very semiotic-material existence creates worlds in which pricing cannot be simply imposed from an 'outside' (be it political power or capital as such); rather, valuation is the outcome of a complex set of intra-actions inside the worlds in which the clashes of valuation unfold. In The Laws of the Markets Callon (1998) gives a description of this process: in situations of extreme uncertainty actors do not perform their calculations (and subsequently recognise opportunities) by getting help from outside the networks in which they operate but use their connections and knowledges inside to arrive at the best possible calculations. Economics is just one of these calculative tools. In other words, economics does not describe markets but performs, modifies and revises ways to judge in the markets. The culture of valuation is a culture in which different calculative agencies operate alongside other social institutions to economise the world and make it tradable.

Central to this argument is that every tangible or intangible object or activity can be potentially valued. What it takes to realise this potential is the design of an appropriate technology of counting and measuring that ensures the comparability of values. This is essentially a technology of temporality. Cultures of valuation are sustained by technologies for appropriating the future (Rona-Tas and Hiss 2011, 226). Social studies of finance weave temporalities, technologies, social interactions and market uncertainties into stories about managing ontological contingency that defy both neoclassical economics as well as the received stories of critical political economy. Calculative agencies are not an instrument of control 'in the hands of capital', as critical political economy would assert, or, on the other hand, mere instruments for achieving and maintaining perfect markets, as neoclassical economists would assume. Calculative agencies and the resulting contingency are 'ontologically real' (Smith 2011, 278); they are embedded in the everydayness, in the materiality of current societies and in the systems of reproduction and production of the Global North. That contingency is ontological means that it is before the actors that engage 
with it. What then one can take from social studies of finance before moving ahead is something very important: our semiotic-ontological access to the world is organised through cultures of valuation to such extent that one cannot simply withdraw from these cultures without dismantling one's own existence.

Although social studies of finance have provided vivid accounts of the inner life of financial markets, their self-proclaimed view that they provide a better insight ${ }^{17}$ into how financial markets and the involved actors work, think and act or even better explanations of the recent crises and the uncontrollability of those markets is overstated. Instead of just explaining financialisation, social studies of finance rather constitute one of the components that perform biofinancialisation. Social studies of finance are not just a response to the proliferation of complex technologies of valuation and their inherent instability but a continuation of them. And it is because of this tight continuity of social studies of finance and biofinancialisation that the utility of social studies of finance for the project of this paper evaporates as soon as it provides us with the possibility to overcome the analytical limitations of political economy and its critiques. This is simply because social studies of finance come to perform and to reproduce biofinancialisation, the very mode of existence that made them possible. The ontological contingency and indeterminancy of valuation does not allow us to fall back on Marxist and post-Marxist political economic analysis of value production. However, in political terms, we can neither remain within the realist preoccupation of social studies of finance that is transfixed on delivering neat accounts of the intricacies of pricing and valuation without providing a political analysis of the social and material conflicts traversing biofinancial societies. So what is to be done? What is politics in these conditions, and is an autonomous politics as we know it from the past four decades possible today?

\section{$\underline{\text { Politics and social science fiction }}$}

Autonomy refers to the idea that social conflicts and social movements drive social transformation instead of just being a mere response to (economic and social) power. ${ }^{18}$ Böhm et al. (2010) discuss how autonomous politics in various configurations--e.g. autonomy as a self-valorising process of one's own labour outside of capital, autonomy as a negative relation to state power, or autonomy as independence from global hegemonic development policies-are often implicated in reproducing the conditions that they seek to challenge. On the other hand though, autonomy produces an excess of practices and social spaces that 'opens up frontiers of resistance and change towards radical practices, an equal society and selforganization' (Böhm et al. 2010, 28). How can this excess be conceived when biofinancialisation becomes both ever present and untouchable?

As we have argued throughout this paper, the core characteristic of biofinancial accumulation is neither immaterial production nor the infrastructures of information technologies and algorithmic valuation nor the underlying networks of social cooperation but rather that biofinancialisation becomes molecularised in flesh, in code and in matter. It alters the very composition, the material infrastructure, of bodies and forms of life. Biofinancialisation becomes fleshly, more than just the exercise of command over life and flesh; biofinancialisation becomes ecology, more than just a system for accelerating accumulation. Biofinancialisation is materially engrained into the affects, the muscles, the sociability, the 
desires, the lifeworlds of working people, non-human others and things. It is impossible to think of autonomy in these conditions as independence from capital, state power and hegemonic globalisation; rather the only possible meaning of autonomy here is organising, experimenting and inventing new forms of life in the midst of existing social and material constraints. Politics is less about the autonomy from social institutions and more about recombining materialities that instigate social and ecological justice. ${ }^{19}$ Autonomy here means, paradoxically, organising interdependences that allow for creating ways of being--other forms of life--that divert existing modes of existence in unexpected directions.

When cultures of valuation and value production fuse onto the ontological fabric of life, novel ways of organising and alternative world-making practices start to emerge. What is an adequate way to conceive these emerging alternative forms of political organisation? Rather than a political economy of autonomy or a social studies of finance and valuation, we think of social science fiction as a possible way to approach the autonomy of the political in biofinancial societies. A hybrid of social science and science fiction that allows for alternative concepts, tropes, and methods to evolve in order to conceive how other forms of life can be created. Social science fiction has a long tradition in science fiction itself: Ursula Le Guin, Samuel Delany and Philip K. Dick, for example, deconstruct present social order by creating alternative and possible future societies. In other words, social science fiction uses not only technoscientific knowledge and natural science but also social science to interrogate the limits of current social organisation and social relations and experiment with creating an immediate experience that allows other alternatives to be imagined as possible. Building on works that bring social science to speculative fiction (social science fiction) here we attempt to bring speculative thought to social science research (social science fiction) in order to create a language and a practice that allows us to fabulate ${ }^{20}$ about the autonomy of politics in biofinancial societies. Fabulation is more than the cultivation of alternative visions of future societies: it is about experimenting with alternative tropes of enunciation and about putting in motion alternative worlds of existence. Social science fiction as we use it here is about changing the conditions of experience in order to make alternative futures possible. The future is here. What follows is a short experiment in reading biofinancialisation through the science fiction trope of terraformation.

\section{Terraforming Earth ${ }^{\mathrm{TM}}$}

Semiocapital, biocapital, infocapital, neurocapital--it is inherent to productionism to seek and open new frontiers. The frontier of life in biofinancial societies is not one that resembles the colonial appropriation of natural creations. Biofinancialisation is not about conquering ecological resources that are necessary to sustain life; rather, biofinancialisation is an experimental project entailing the constant remixing of the cultural, the biotic and the abiotic. Bios in biofinancialisation is not about nature, it is about flesh and matter. HBSC analysts and marketeers tell us in one of the adverts of their 'In the future' campaign that '[i]n tomorrow's global economy, every resource will be counted. ${ }^{21}$ The advert shows a salmon against an aseptic white background imprinted with a barcode on its skin. The main headline states that '[i]n the future, the food chain and the supply chain will merge'. This future starts today. It is a future where every common nature-cultural creation will be transformed to a service provider 
and a resource. This moment is only possible when code and matter fuse into each other. When this fusion touches upon the very materiality of human and animal bodies, the geobody, it no longer seems to be able to be sufficiently described by the term enclosure of the commons. When the digital and the material, information and life, the barcode and the salmon skin are intrinsically imprinted onto each other, matter as such and the biota more specifically do not lie outside of the process of biofinancialisation. The commons are not external and against their enclosures, neither can one say that there are degrees of enclosure: it is untenable to assume that some things are fully enclosed in the system of accumulation, while others are fully outside of it and in between are things that are only partly enclosed (such as air, water, internet, culture). When matter in its ontological composition is a frontier, both the commons and their enclosures exist inside each other. There is no commons versus biofinancialisation but biofinancialisation in the commons. The subjectivity of working people, the body of the commons and the eco-body of earth are not separable from the current architectures of accumulation. Everything belongs one hundred per cent to the res communes and one hundred per cent to the current regime of biofinancial accumulation. Terraformation.

The idea of terraformation is since its first appearance in the 1930s and 1940s not only a returning science fiction topos. It is also used to describe the science of remodelling and remaking of the biosphere of a planetary body in order to make it

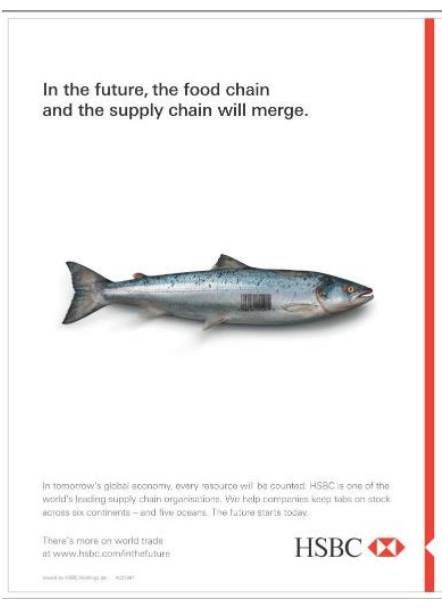

Figure 1 'In the future, the food chain and the supply chain will merge' (advertisement). HSBC Holdings plc. hospitable to humans and to enable it to support life (e.g. Beech 2009; Fogg 1995). Terraforming in science fiction speaks to a territory--outer space--that is currently more desired and disputed than the Antarctic or the high seas of earth. ${ }^{22}$ Terraformation is equally about science fiction, technoscience and colonisation as much as it is about geopolitics, value production and the valuation and financialisation of space. ${ }^{23}$ This is because terraformation does not only apply to extraterrestrial geoengineering. One could instead justifiably say that humans have been terraforming earth for hundreds of years by changing its very ontological constitution, even if only inadvertently. Or one could say that humans have damaged earth so badly that we need now to terraform it. Both versions culminate in one and the same event where terraformation becomes a capital enterprise: Terraforming Earth ${ }^{\mathrm{TM}}$. Its primary actors, though, are not those spectral entrepreneurs that apparently move and shape the world for the rest of us, but the processes that measure and evaluate earth's spaces and matter. Terraforming Earth ${ }^{\mathrm{TM}}$ is much closer to our realities than even its most dedicated believers, probably some NASA technocrats, would have thought. It is as close as the worlds that science fiction has morphed into our experience: social science fiction.

But unlike the vision of terraforming other planets, Terraforming Earth ${ }^{\mathrm{TM}}$ does not have a blueprint for action. Humans do not and will not terraform earth following some preconception of what 'earth' is or can be. Humans are terraforming earth without a prototype and a plan. We don't know what earth as such is or was or even what it is able to do or become as a precondition of our capability to terraform it appropriately. Rather Terraforming Earth ${ }^{\mathrm{TM}}$ is a simulacrum of itself, a practice of immersion in material 
experimentation, rather than of agency. Terraforming Earth ${ }^{\mathrm{TM}}$ is the outcome of the multiplication of climate change, acid oceans, the $6^{\text {th }}$ extinction, synthetic biology, nuclear power, virtual space, big science and the biofinancial logic that underlies increasingly every social-material encounter. On a planetary scale it unfolds without unified agency, without intentionality. Terraforming Earth ${ }^{\mathrm{TM}}$ has no master plan, only effects, that can be purportedly measured, and their future impacts evaluated. The algorithmic moves of biofinance are only graspable as global motions on another planet as close as ours.

\section{$\underline{\text { Material returns }}$}

When ecologies of existence become terraformed, the material returns to politics: reclaiming everyday materiality by actively recomposing and rearticulating it. We take inspiration here from James Clifford's (2001; 2004) work on indigenous politics as rooted articulations (and disarticulations) of variously scaled histories, traditions and practices on the uneven and variegated terrain of global space and time. But here we want to think of articulation beyond cultural practice and semiosis. We are thinking of a process of articulation that operates on the level of matter. In the social science fiction story we are telling these are material articulations. Practices that disarticulate and rearticulate matter into unexpected organic and inorganic ensembles grounded in the material constraints of biofinancial life: How can we encounter the damage that valuation has inflicted on salmon stocks that capture the entrepreneurial fantasies of HSBC marketeers? How can the commons be expanded when they are fused with biofinance?

Octavia Butler offers an alternative vision of organising life in Xenogenesis (2000): ontological organising, the creation of new couplings with other beings and things and new kinds of life able to respond to altered environments and to create liveable words. If one wants to talk about autonomy in biofinancial societies then this is about reciprocal becomings with other things, materials and living organisms that let alternative ontologies of existence emerge. ${ }^{24}$ In Haraway's (2010) words, it is about creating 'a seed bag for terraforming with earth others.' Terraformation from below. We read Kim Stanley Robinson's Mars trilogy (1992-1996) and his depictions of the technoscientific and social processes of Mars' terraformation as something more than alternative future visions. These are devices for modifying our experience so that we become able to adapt and readapt politics and autonomy to conditions where there is no prior state of being to fall back or no 'future wholeness which may yet save us' (Rose 2004, 24). ${ }^{25}$

As the material returns (and changes) the meaning of autonomy in politics, so its returns have important implications for the commons. The practice of the commons is not politics; it is 'commoning' as Linebaugh (2008) calls the social-material practices that are firmly embedded in the cultural and material contingencies in which they take place and that create non-enclosed worlds of existence. ${ }^{26}$ But in the social, political, material conditions described throughout this paper commoning is rather about making new symbiotic and epigenetic mixtures of algorithmic valuations, human bodies, things and ecologies in unnatural compounds of commonly shared life. Probably this is the difference between the politics of resistance to biofinancialisation and the alternative politics that can emerge within it: resistance presupposes that biofinance can be removed from human bodies, ecologies and 
the commons. Commoning moves the terrain of conflict from the social to the material: it explores how affected bodies and ecologies can be recombined internally to divert to other forms of life. From biofinance to symbiofinance. Autonomy then lies in these compounds of algorithmic code, material processes and bodies, not outside or against them but in the remaking and reclaiming of their materiality.

\section{Notes}

${ }^{1}$ See Beverungen et al. (2013), Lilley and Lightfoot (2014), Bryan et al. (2012).

${ }^{2}$ If one reads Huw Beynon's (2011) account of labour conflict in Britain not as a story of decline but from a perspective that highlights the leading role of labour in social transformation, one can see how labour became a powerful force of change that needed to be controlled and tamed. In addition to organised labour, sabotage and subversion in the workplace, uncoordinated wildcat strikes, absenteeism and high staff turnover, the refusal of housework--all different strategies for exiting work weakened as a movement after the 1980s.

${ }^{3}$ See Cameron et al. (2010).

${ }^{4}$ See also Bryan and Rafferty (2006) and Langley (2008).

${ }^{5}$ For different understandings of biofinancialisation that have influenced the position presented in this paper see French and Kneale (2012), Fumagalli (2011), Marazzi (2010), Martin (2002), Murphy (2013).

${ }^{6}$ See for example the fascinating research of Kortright (2012) on transgenic rice and how the promise of a high yielding crop shapes geopolitics, agro-food investments and research.

${ }^{7}$ See various approaches to the construction of instruments that allow the quantifications of different values in Callon et al. (2007), Karpik (2010).

${ }^{8}$ For different accounts on these practices see Smith (1999) and Stark (2009).

${ }^{9}$ Following a periodization where second capitalism, which is industrial capitalism (1800-1970) came after a long period of instability during the $19^{\text {th }}$ century to replace first capitalism: merchant capitalism, which depended on the exploitation of slave labour and the territories of the colonies.

${ }^{10}$ There is no comprehensive research about how these two dimensions of the accumulation regime contribute to value production in Global North societies. Paul Thompson, for example, arguing from the perspective of Labour Process Theory emphasizes that the socialisation of value production is empirically unsubstantiated and that the core site of value production remains the workplace, be it the manufacturing shop floor, the office or the retail space (Thompson 2005). But these claims are equally unsubstantiated; there is no extensive study, to our knowledge, that would support them either. The debates initiated by Labour Process Theory on the socialisation of value production seem to be merely ideological.

${ }^{11}$ In Labour Process Theory the workplace is examined in a relative isolation from the wider social relations and technological change (for a discussion see Lilley et al. 2004). This perspective can produce a wealth of insights into control and subordination in the workplace but it misses broader social transformations that affect the workplace. For example in the discussion of labour process in call centres Warhurst et al. (2009) clearly say that call centre workers are not unskilled but need to have considerable social and interactive skills and competencies. However, they refuse to discuss how are these skills acquired or learned, how they develop and how they are nurtured. They thus refuse to see the social transformations that make workplace exploitation possible.

${ }^{12}$ See Lilley and Lightfoot (2014).

${ }_{13}$ Originally Tronti (2005), see also Bowring (2002), Weeks (2011).

${ }^{14}$ Such as Gibson-Graham (2006); see also Tsianos et al. (2012).

${ }^{15}$ See for example research on the valuation of complex financial instruments (Mackenzie 2012), research on the performative capabilities of economics (Millo and Mackenzie 2009) or studies in material and semiotic arrangements used for the calculation of economic objects (Knorr-Cetina and Preda 2006).

${ }^{16}$ The main driver behind this is the computerization of financial markets, that is automatic trading as well as efinance platforms. 
${ }^{17}$ As for example Mackenzie (2009) implies.

${ }^{18}$ A position which primarily was developed in regards to the role of working class struggles in historical change: capital is not the driving force of change; instead workers' refusal and insubordination force capital to reorganise itself (Cleaver 1992; Negri 1988). This perspective on autonomy is of course limited to the relation between capital and labour but the question of autonomous politics exceeds this relation. In the wake of the new social movements that emerged from the Zapatista encuentros and the Seattle mobilisations in the mid/end of the 1990s autonomy is explored in relation to technoscience, culture, feminist politics, and the struggles for the commons (Böhm et al. 2010; Dinerstein 2010; Papadopoulos et al. 2008).

${ }^{19}$ See also Papadopoulos (2014).

${ }^{20}$ From Bergson via Deleuze 'the goal of fabulation is to break the continuities of received stories and deterministic histories, and at the same time to fashion images that are free of the entangling associations of conventional narratives and open to unspecified elaboration in the construction of a new mode of collective agency' (Bogue 2007, 106).

${ }^{21}$ See www.hsbc.com/inthefuture (website last assessed 15.3.2014). The series of adverts including the supply chain advert discussed here were issued by HSBC Holdings plc. (AC22967).

22 See Parker and Bell (2009).

${ }^{23}$ See Collis and Graham (2009) and more broadly Cameron et al. (2010).

${ }^{24}$ On alter-ontologies see Papadopoulos (2011) and Puig De La Bellacasa (2010).

${ }^{25}$ The extended quote from Deborah Bird Rose reads: 'Central to my argument is the proposition that there is no former time/space of wholeness to which we might return or which we might resurrect for ourselves. Nor is there a posited future wholeness which may yet save us. Rather, the work of recuperation seeks glimpses of illumination, and aims towards engagement and disclosure. The method works as an alternative both to methods of closure and suspicion and to methods of proposed salvation' (Rose 2004, 24). Many of the questions discussed in this paper are inspired by work in ecological humanities such as Rose and Van Dooren (2011).

${ }^{26}$ See also Puig De La Bellacasa (2014) and Papadopoulos (2012). 


\section{References}

Alberti, G (2011) Transient working lives: Migrant women's everyday politics in London's hospitality industry. School of Social Sciences, Cardiff University, Cardiff: Unpublished PhD dissertation.

Barbagallo, C, Federici, S (2012) Special Issue "Care Work" and the Commons. The Commoner 15.

Barbier, J-C, Hawkins, P 2012. 'Evaluation cultures : sense-making in complex times' Comparative policy evaluation. New Brunswick: Transaction Publishers.

Beckert, J, Aspers, P 2011. 'The worth of goods : valuation and pricing in the economy'. Oxford: Oxford University Press.

Beech, M (2009) Terraforming: the creating of habitable worlds. New York: Springer.

Beverungen, A, Dunne, S, Hoedemaekers, C (2013) The financialisation of business ethics. Business Ethics: A European Review 22(1): 102-117.

Beynon, H (2011) Engaging Labour: British Sociology 1945-2010. Global Labour Journal 2(1): $5-26$.

Bifo Berardi, F (2009) Precarious Rhapsody. Semiocapitalism and the pathologies of post-alpha generation: Minor Compositions.

Bifo Berardi, F (2011). 'Cognitarian subjectivation' in Aranda, J., Wood, B.K. and Vidokle, A. (eds.) Are you working too much? Post-Fordism, precarity, and the labor of art. Berlin: Sternberg Press.

Bogue, R (2007) Deleure's way : essays in transverse ethics and aesthetics. Aldershot: Ashgate.

Böhm, S, Dinerstein, A C, Spicer, A (2010) (Im)possibilities of Autonomy: Social Movements in and beyond Capital, the State and Development. Social Movement Studies 9(1): 17-32.

Bollier, D (2008) Viral spiral : how the commoners built a digital republic of their own. New York: New Press.

Bowring, F (2002) Post-Fordism and the end of work. Futures 34: 159-172.

Bryan, D, Martin, R, Montgomerie, J, Williams, K (2012) An important failure: knowledge limits and the financial crisis. Economy and Society 41(3): 299-315.

Bryan, D, Rafferty, M (2006) Capitalism with Derivatives. A Political Economy of Financial Derivatives, Capital and Class. New York: Palgrave Macmillan.

Callon, M (1998) The laws of the markets. Oxford: Blackwell. 
Callon, M, Millo, Y, Muniesa, F 2007. 'Market devices' Sociological review monographs. Oxford: Blackwell Publishing.

Cameron, A, Lightfoot, G, Lilley, S, Brown, S D (2010) Placing the 'post-social' market: Identity and spatiality in the xeno-economy. Marketing Theory 10(3): 299-312.

Cleaver, H (1992). 'The Inversion of Class Perspective in Marxian Theory: From Valorisation to Self-Valorisation' in Bonefeld, W., Gunn, R. and Psychopedis, K. (eds.) Open marxism. Volume II: Theory and practice. London: Pluto press.

Clifford, J (2001) Indigenous Articulations. The Contemporary Pacific 13(2): 468-490.

Clifford, J (2004) Looking Several Ways : Anthropology and Native Heritage in Alaska. Current Anthropology 45(1): 5-30.

Collis, C, Graham, P (2009) Political geographies of Mars: A history of Martian management. Management \& Organizational History 4(3): 247-261.

De Angelis, M, Harvie, D (2009) 'Cognitive Capitalism' and the Rat-Race: How Capital Measures Immaterial Labour in British Universities. Historical Materialism 17(3): 3-30.

Dinerstein, A C (2010) Autonomy in Latin America: between resistance and integration. Echoes from the Piqueteros experience. Community Development Journal 45(3): 356-366.

Duménil, G, Lévy, D (2005). 'Costs and benefits of neoliberalism. A class analysis' in Epstein, G.A. (ed.) Financialization and the world economy. Cheltenham: Edward Elgar.

Fogg, M J (1995) Terraforming : engineering planetary environments. Warrendale, PA: Society of Automotive Engineers.

French, S, Kneale, J (2012) Speculating on Careless Lives. Journal of Cultural Economy 5(4): 391406.

Fumagalli, A (2011) Twenty theses on cognitive capitalism (cognitive biocapitalism). Angelaki 16(3): 7-17.

Gibson-Graham, J K (2006) A postcapitalist politics. Minneapolis: University of Minnesota Press.

Haraway, D J (2010). 'Sowing Worlds: a Seed Bag for Terraforming with Earth Others' in Helen, M.G.a. and Merrick (eds.) Beyond the Cyborg: Adventures with Haraway: Columbia University Press.

Karpik, L (2010) Valuing the unique : the economics of singularities. Princeton: Princeton University Press. 
Knorr-Cetina, K, Preda, A 2006. 'The sociology of financial markets'. Oxford: Oxford University Press.

Kortright, C (2012) C4 Rice and Hoping the Sun Can End Hunger: Tales of Plants, Evolution, Transgenics and Crisis. PhD thesis, University of California Davis.

Langley, P (2008) The everyday life of global finance: saving and borrowing in Anglo-America. Oxford: Oxford University Press.

Lilley, S, Lightfoot, G (2014) The embodiment of neoliberalism: exploring the roots and limits of the calculation of arbitrage in the entrepreneurial function. The Sociological Review 62(1): 68-89.

Lilley, S, Lightfoot, G, Amaral, P (2004) Representing organization: knowledge, management, and the information age. Oxford: Oxford University Press.

Linebaugh, P (2008) The Magna Carta manifesto : liberties and commons for all. Berkeley, Calif.: University of California Press.

Mackenzie, D (2009) Beneath all the toxic acronyms lies a basic cultural issue. Financial Times November 26.

Mackenzie, D (2012) Knowledge production in financial markets: credit default swaps, the ABX and the subprime crisis. Economy and Society 41(3): 335-359.

Marazzi, C (2010) The violence of financial capitalism. Los Angeles: Semiotext(e).

Martin, R (2002) Financialization of daily life. Philadelphia: Temple University Press.

Millo, Y, Mackenzie, D (2009) The usefulness of inaccurate models : Towards an understanding of the emergence of financial risk management. Accounting Organizations and Society 34(5): 638-653.

Moulier Boutang, Y (2012) Cognitive Capitalism. Cambridge: Polity Press.

Murphy, M (2013). 'Economization of life: Calculative infrastructures of population and economy' in Rawes, P. (ed.) Relational Architectural Ecologies: Architecture, Nature and Subjectivity. London: Routledge.

Negri, A (1988) Revolution retrieved : writings on Marx, Keynes, capitalist crisis, and new social subjects (1967-83). London: Red Notes.

Papadopoulos, D (2011) Alter-ontologies: Towards a constituent politics in technoscience. Social Studies of Science 41(2): 177-201.

Papadopoulos, D (2012) Worlding justice/Commoning matter. Occasion: Interdisciplinary Studies in the Humanities 3 (March 15, 2012 ): http://occasion.stanford.edu/node/79. 
Papadopoulos, D (2014) Politics of Matter: Justice and Organisation in Technoscience. Social Epistemology 28(1): 70-85.

Papadopoulos, D, Stephenson, N, Tsianos, V (2008) Escape routes. Control and subversion in the 21st century. London: Pluto Press.

Parker, M, Bell, D F 2009. 'Space travel and culture : from Apollo to space tourism' Sociological review monographs. Malden, MA: Wiley-Blackwell/Sociological Review.

Puig De La Bellacasa, M (2010) Ethical doings in naturecultures. Ethics, Place \& Environment. A Journal of Philosophy \& Geography 13(3): 151-169.

Puig De La Bellacasa, M (2014) Encountering Bioinfrastructure: Ecological Struggles and the Sciences of Soil. Social Epistemology 28(1): 26-40.

Rona-Tas, A, Hiss, S (2011). 'Forecasting as Valuation: The Role of Ratings and Predictions in the Subprime Mortgage Crisis in the United States' in Beckert, J. and Aspers, P. (eds.) The worth of goods : valuation and pricing in the economy. Oxford: Oxford University Press.

Rose, D B (2004) Reports from a wild country : ethics for decolonisation. Sydney, NSW: University of NSW Press.

Rose, D B, Van Dooren, T (2011) Unloved Others: Death of the Disregarded in the Time of Extinctions [special issue]. Australian Humanities Review 50.

Smith, C W (1999) Success and survival on Wall Street: understanding the mind of the market. Lanham, Md. ; Oxford: Rowman \& Littlefield.

Smith, C W (2011). 'Coping with Contingencies in Equity Option Markets: The "Rationality" of Pricing' in Beckert, J. and Aspers, P. (eds.) The worth of goods : valuation and pricing in the economy. Oxford: Oxford University Press.

Stark, D (2009) The sense of dissonance : accounts of worth in economic life. Princeton, N.J.: Princeton University Press.

Thompson, P (2005) Foundation and Empire: A critique of Hardt and Negri. Capital \& Class 29(2): 73-98.

Tronti, M (2005) The Strategy of Refusal. Libcom.org.

Tsianos, V, Papadopoulos, D, Stephenson, N (2012) This Is Class War from Above and They Are Winning It: What Is to Be Done? Rethinking Marxism 24(3): 448-457.

Warhurst, C, Thompson, P, Nickson, D (2009). 'Labor process theory: Putting the materialism back into the meaning of service work' in Korczynski, M. and Macdonald, C.L. (eds.) Service work. Critical perspectives. London: Routledge. 
Weeks, K (2011) The problem with work. Feminism, Marxism, antiwork politics, and postwork imaginaries. Durham: Duke University Press.

Zibechi, R (2011) Territorien des Widerstands. Eine politische Kartografie der urbanen Peripherien Lateinamerikas Hamburg: Assoziation A. 
